\section{RESENHA DO}

LIVRO EUNICE

KATUNDA:

MUSICISTA

BRASILEIRA, DE

CARLOS KATER

RevistaMúsica | vol. 19, n.2 |

pp. 289-298 | jul. 2019

\section{Marisa Milan Candido}

marisamilan@usp.br | USP

Eliana M. de A. Monteiro da Silva

ms.eliana@usp.br | USP

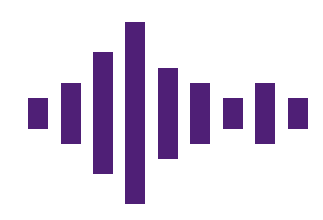

REVIEW OF CARLOS

KATER'S BOOK, EUNICE

KATUNDA: BRAZILIAN

MUSICIAN

Recebido em: 17/05/2019

Aprovado em: 15/06/2019

\section{RESUM0}

A resenha do livro Eunice Katunda: musicista brasileira, escrito por Carlos Kater e publicado em 2001 pela Editora Annablume, tem como objetivo apontar seu conteúdo e os principais tópicos abordados. O livro, que foi o primeiro trabalho realizado acerca da pianista e compositora, conta com um esboço biográfico da artista, um catálogo de obras inédito de sua produção, além de cartas e textos de sua própria autoria.

\section{PALAVRAS-CHAVE:}

Resenha; Eunice Katunda; Carlos Kater.

\section{ABSTRACT}

The review of the book Eunice Katunda: Brazilian musician, written by Carlos Kater and published in 2001 by Editora Annablume, aims to highlight its content and the main topics covered. The book, which brings the first research realized about the pianist and composer, features a biographical sketch of the artist, a catalog of unpublished works of her production, as well as letters and texts of her own.

KEYWORDS:

Review; Eunice Katunda; Carlos Kater. 


\title{
RESENHA DO LIVRO EUNICE KATUNDA: MUSICISTA BRASILEIRA, DE CARLOS KATER
}

\author{
Marisa Milan Candido \\ marisamilan@usp.br | USP \\ Eliana M. de A. Monteiro da Silva \\ ms.eliana@usp.br|USP
}

\section{Introdução}

Publicado em 2001 pela Editora Annablume, o livro Eunice Katunda: musicista brasileira, escrito por Carlos Kater, foi o primeiro trabalho realizado sobre a pianista e compositora Eunice Katunda. Antes desta publicação, seu nome (Eunice Katunda) era apenas citado em livros de história da música, como em Música contemporânea brasileira (1981), de José Maria Neves, e a partir da quinta edição revisada e ampliada de História da música no Brasil (2000), de Vasco Mariz. ${ }^{1}$

Carlos Kater, musicólogo e autor do livro aqui mencionado, é um dos principais pesquisadores sobre o movimento Música Viva - no qual Eunice Katunda foi integrante - tendo publicado também Música Viva e H. J. Koellreutter: movimentos em direção à modernidade (2001) e H. J. Koellreutter: catálogo de obras (1997). A coleta de materiais para a pesquisa sobre Eunice Katunda foi realizada na década de 1980 pelo autor, no período de sua atuação como professor no Instituto de Artes da Universidade Estadual Paulista - UNESP.

Para a elaboração do trabalho - que segundo Kater foi realizado por ele próprio no âmbito de uma pesquisa maior desenvolvida junto à UNESP - foram recuperados, organizados, classificados e microfilmados arquivos como cartas, programas de concerto, partituras, entre outros documentos que encontravam-se disponíveis em bibliotecas públicas, no acervo pessoal de Eunice e também de músicos e amigos da artista. Entrevistas com a compositora, realizadas ao longo dos anos de 1985 e 1986, também auxiliaram na elaboração da biografia, catálogo de obras e histórico comentado que compõem o livro aqui enfocado. Sua extensão é de 174 páginas.

O sumário do livro é dividido em onze partes: Apresentação, Introdução, Um Esboço biográfico, Textos de Eunice Katunda, Catálogo de Obras, Índice Remissivo, Listagem por ordem alfabética, Correspondências, Bibliografia, Anexos e Partitura do Negrinho do Pastoreio.

\footnotetext{
${ }^{1}$ Kater observa que o nome de Eunice Katunda foi encontrado em importantes obras de referência internacional, como Who is Who of Music, Delta Larousse, Enzyclopedie der Modern Musik.
} 
A “Apresentação” do livro, escrita por Maria de Lourdes Sekeff - à época também professora do Instituto de Artes da Universidade Estadual Paulista - destaca a importância do livro ao resgatar e expor a trajetória de Eunice Katunda que, segundo ela, "foi uma das mais significativas propulsoras da música brasileira contemporânea”, e que até o momento de publicação do livro, era apenas uma personalidade esquecida na musicologia brasileira. Também ressalta a relevância da pesquisa de Carlos Kater, realizada com base em documentos, cartas, entrevistas, entre outras fontes primárias, assim como a disponibilização de parte deste arquivo no próprio livro.

Da mesma maneira, Kater discorre na Introdução de seu livro a importância de resgatar a figura de Eunice Katunda, para, de certa forma, preencher uma das lacunas da musicologia brasileira da época. Salienta também sua intenção em disponibilizar alguns textos, documentos e a partitura da obra Negrinho do pastoreio, de Eunice Katunda, como forma de contribuir para o conhecimento e divulgação de sua vida e obra.

A seção denominada "Esboço biográfico" ocupa 27 páginas do livro (pp. 13-39) e consiste em um relato acerca da trajetória pessoal e, principalmente, musical de Eunice Katunda. Kater começa o texto com informações acerca da iniciação de Eunice ao piano que, segundo ele, ocorreu com a chegada do instrumento em sua casa, quando tinha três anos de idade. A partir disso, segue com informações acerca das suas aulas de piano com os professores Mima Oswald, Branca Bilhar e Oscar Guanabarino, além de apresentar os principais recitais e concertos realizados por ela.

Também no "Esboço biográfico" se encontra o relato sobre o casamento de Eunice com o matemático Omar Catunda em 1934 e sua consequente mudança do Rio de Janeiro para a cidade de São Paulo. Desta fase são seus novos professores de piano e de matérias teóricas Furio Franceschini, Marietta Lion e Camargo Guarnieri e se destacam vários concertos e apresentações, entre elas a sua turnê em Buenos Aires no ano de 1944, por recomendação do compositor Villa-Lobos.

O texto segue com o retorno de Eunice Katunda para o Rio de Janeiro em 1946, no qual aponta sua ligação com o professor Hans-Joachim Koellreutter e com o movimento e grupo de compositores Música Viva. Esta é a parte mais extensa da biografia elaborada sobre Eunice, já que expõe suas atividades junto ao Música Viva, sua atuação como compositora, pianista, seu envolvimento com a música contemporânea da época e, por fim, sua estadia na Europa no final da década de 40. Este trecho ainda apresenta as principais ligações e atividades desenvolvidas por Katunda na Europa, como concertos, cursos, estreias de peças, além de seu contato e convívio com grandes personalidades da época, como o regente e professor Hermann Scherchen e os compositores Luigi Nono e Bruno Maderna. 
A desarticulação do grupo de compositores Música Viva, que ocorreu entre os anos de 1948 e 1950, e principalmente a postura de Eunice Katunda diante deste episódio também são apontados em Esboço biográfico. O texto, assim como as citações da própria Eunice ao longo das páginas, deixam claro que no início, especificamente no ano de 1948, ela foi contra a desarticulação do grupo, e que dois anos depois acabou mudando sua postura, o que coincidiu com a publicação da Carta aberta aos músicos e críticos do Brasil, escrita em 1950 por Camargo Guarnieri.

Após seu rompimento com Koellreutter e com o grupo Música Viva, são evidenciadas a nova postura de Eunice Katunda frente à música contemporânea da época, bem como suas novas preocupações contra o formalismo da estética dodecafônica e a favor de elementos característicos da música nacional. Deparamos- nos com citações de seus textos nomeados como Atonalismo, dodecafonia e música nacional e em A Bahia e os brasileiros. ${ }^{2}$ Pesquisas realizadas no nordeste do Brasil, textos e peças decorrentes destas experiências, como, por exemplo, Bahia dos cinco sentidos e Sonata de louvação também são citados ao longo da narrativa, embora este assunto não seja aprofundado com maiores detalhes.

Outras atividades de Eunice na década de 50 também são relatadas neste capítulo, como os concertos e os cursos de introdução a música realizados no Museu de Arte Moderna de São Paulo. Sua atuação como regente e arranjadora a frente do Coral Piratininga e, principalmente, do programa Musical Lloyd Aéreo - realizado na Rádio Nacional de São Paulo, onde também atuou como pianista solo -, também merecem destaque. A respeito dessa atuação junto a rádio, Kater discorre acerca dos arranjos e adaptações de Eunice Katunda a partir de músicas típicas brasileiras, seu papel na divulgação de compositores contemporâneos desconhecidos do meio musical da época por meio de primeiras audições de suas peças, 3 incluindo, por fim, trechos de críticas de jornais da época, escritos por Arnaldo Câmara Leitão em O Tempo e no Diário de São Paulo.

A atividade de Eunice como pianista também é enfatizada ao longo do texto, que conforme mencionado anteriormente, apresenta os principais recitais e concertos realizados, assim como os prêmios recebidos por sua atuação. Aponta ainda que a fase de maior domínio técnico e interpretativo pode ser considerada a partir do ano de 1942, que coincide com sua 4 a colocação no concurso Colúmbia Concerts, e que se intensifica com a sua colaboração como pianista junto ao movimento Música Viva. Em relação à sua ida a URSS no ano de 1953, Kater cita que Eunice realizou apresentações individuais na

\footnotetext{
${ }^{2}$ Estes textos são disponibilizados no capítulo seguinte do livro intitulado Textos de Eunice Katunda.

3 Como exemplo pode ser observada a estreia da obra Peixes de prata, de Gilberto Mendes.
} 
Rádio de Moscou, embora não disponibilize maiores detalhes deste evento. Da mesma maneira, seu contato com o universo da música popular é relatado de maneira resumida, pois são citados seus improvisos ao piano em conjunto com o violinista Baden Powell, no João Sebastião Bar no ano de 1962, e seu contato com Vinícius de Moraes, decorrente de uma entrevista para sua coluna musical na revista Cláudia.

Sua atuação como pianista na década de 60, considerada pelo autor como o período mais maduro da carreira de Eunice Katunda como intérprete, também é relatada no presente capítulo. Sobre este período, Kater cita as turnês realizadas nos Estados Unidos no ano de 1968, assim como os recitais realizados no Brasil após seu retorno dos Estados Unidos, em decorrência de problemas causados por sua empresária local. As descrições destas apresentações são acompanhadas por trechos de críticas, como as escritas por Theodore Strongin no The New York Times, e por Antonio Hernandez, em O Globo. Em seguida, é apresentada uma lista de compositores que dedicaram peças à Eunice Katunda, como Bruno Maderna, Cláudio Santoro, Koellreutter, entre outros.

Algumas dificuldades sofridas por Eunice em relação à sua época, decorrentes, segundo Kater, "aparentemente menos como mulher e mais como pessoa engajada ideologicamente", são relatadas no texto. ${ }^{4}$ Cita, inclusive, o episódio em que Eunice foi proibida de entrar no Teatro Municipal de São Paulo, em 1965, às vésperas de um concerto, acusada de ligação com o Partido Comunista, do qual ela já havia se afastado em 1954. Já o fim da biografia relata o episódio em que Eunice Katunda se lamentou publicamente pelo seu rompimento com Koellreutter no $8^{\circ}$ Curso Latino americano de Música Contemporânea, realizado na cidade de São João Del Rey (MG) em comemoração aos quarenta anos de Música Viva, no ano de 1979.

Por fim, Kater menciona que "Eunice Katunda não pode ser considerada uma autora 'nacionalista', no sentido usual e restrito do termo. E isto, no entanto, é igualmente verdadeiro em relação à vanguarda, à experimentação musical”, pois ainda segundo o autor, "o recurso frequente ao folclore e ao popular não se mostra como simples resultante de um compromisso político em obra", da mesma maneira que "o dodecafonismo aparece em suas músicas como recurso técnico, praticamente jamais como característica de linguagem”. Destaca também a maneira visceral de Eunice diante de suas escolhas político-ideológicas e musicais, que em suas palavras "não confinou seu trabalho, nem tampouco sua vida, aos limites vigentes; ousou avançar fronteiras de várias naturezas.”

4 Aqui as dificuldades se referem ao período da Guerra Fria entre as potências EUA e URSS, iniciada pouco depois do fim da Segunda Guerra Mundial, quando o Brasil e outros países latino-americanos viveram situações de grande instabilidade política. 
Após o "Esboço biográfico", o livro apresenta um capítulo com "Textos de Eunice Katunda”. São eles: “Cartas de Macunaíma para o Brasil” (1948), “A minha viagem para a Europa” (1949?), “Atonalismo, dodecafonia e música nacional” (1952), "A Bahia e os brasileiros" (1954-58?), "Riquezas da tradição" (1954) e "Auto-retrato" (198?). O autor compartilha com os leitores sua dúvida acerca do consentimento de Eunice em relação à publicação desses textos, mas decide-se por divulga-los para "restaurar o brilho das cores de um momento que serviu de território para o percurso dessa musicista brasileira. Momento com o qual ela intensamente dialogou e que tão bem é capaz de contextualizar suas ações”. Segundo Kater, há também uma carta da compositora que atesta sua permissão para publicação, escrita em 15/9/1948.

O texto nomeado Cartas de Macunaíma para o Brasil consiste em uma coletânea de correspondências enviadas por Eunice Katunda ao Brasil, datadas entre agosto e outubro de 1948. São relatos, impressões e reflexões de sua viagem à Itália, que realizou para participar do Curso de Regência ministrado por H. Scherchen no XI Festival Internacional de Música Contemporânea, da Bienal de Veneza. Segundo o autor do livro, parte destas correspondências foram publicadas na Folha da Manhã, de São Paulo, no ano de 1949, sob o título Trechos de correspondência da Itália.

Entre os muitos assuntos tratados nas correspondências, como as suas aulas com Scherchen, seus estudos de piano, suas visitas a exposições de arte, entre outros, destacase uma carta datada em 03/10/1948, em que Eunice defende a abertura estética do Música Viva e contraria o afastamento de Santoro em relação ao grupo. A compositora critica, principalmente, a posição do colega em relação a técnica dodecafônica, publicada em carta sob o título Problemas da música contemporânea (SANTORO, 1948, apud KATER, 2001). Em seu texto de 1948, Eunice Katunda afirma que "não há contradição entre o dodecafonismo e o manifesto de Praga. Há sim um sectarismo geral que muitas vezes impede a compreensão clara do problema”.

O segundo texto de Eunice disponibilizado no livro e denominado pelo autor como A minha viagem para a Europa, não possui título e nem data. No entanto, Kater supõe que ele tenha sido escrito no Brasil em abril de 1949. Neste texto, Eunice descreve os cursos, estreias de peças, apresentações realizadas ao piano, seu contato com o professor Hermann Scherchen e com os compositores Luigi Nono e Bruno Maderna, entre muitos outros acontecimentos durante sua estadia na Europa. Dentre os relatos de alguns eventos, Eunice cita sua felicidade pela primeira audição de sua peça orquestral Quatro Cantos à Morte, realizada por Scherchen, na qual descreve que se sentiu "realmente feliz pois poucas pessoas têm a sorte de ouvir sua primeira obra orquestral numa execução 
tão perfeita e numa interpretação tão bela.” Outro fato destacado por ela foi o concerto que realizou, em primeira audição, da peça Ludus Tonalis de Paul Hindemith, na Itália.

Além do relato das atividades de Eunice Katunda na Europa, o texto $A$ minha viagem para a Europa também pode ilustrar o início de seu afastamento em relação ao grupo Música Viva e sua consequente mudança estética composicional. Eunice cita que viu "a tragédia dos compositores que, atingindo um nível altíssimo de conhecimento e de domínio técnico, passam a escrever obras onde a música existe em função dessa técnica [dodecafonismo]. Música em que o compositor se repete e se satisfaz num narcisismo individualista e estéril”. Sua aproximação ao nacionalismo também fica clara ao apontar o interesse dos italianos pela música e pelo folclore brasileiro, assim como ao destacar sua pretensão em retornar à Itália não apenas com um programa de música contemporânea europeia, mas sim com "um belo programa da melhor música erudita sul-americana. E muito folclore, para apresentar em conferências”.

Atonalismo, dodecafonia e música nacional, datado em 1952, corresponde ao terceiro texto de Eunice Katunda disponibilizado neste capítulo. Conforme Kater, o texto, também editado pela revista Fundamentos em 1952, "pode ser considerado um 'documento-manifesto', no qual Eunice enfatiza a ruptura com a linha que vinha sendo imprimida pelo Música Viva e assume confronto direto com H. J. Koellreutter”. Sendo assim, Eunice Katunda critica o dodecafonismo e o atonalismo como um "processo puramente cerebralístico", e se posiciona a favor da composição da música nacional, que segundo ela possui "características melódicas, contrapontísticas, harmônicas, rítmicas, instrumentais, muito definidas".

A Bahia e o brasileiros, de acordo com o autor, consiste em uma transcrição cotejada com o texto original publicado pela revista Fundamentos em 1958, em que Katunda relata o seu contato com as raízes e o folclore da Bahia. No texto, ela aponta a importância de viagens de estudos e de enriquecimento artístico pelo Brasil, assim como defende que artistas devem se apoiar na realidade brasileira, e não em fatores cosmopolitas. Para o autor, Eunice também faz uma referencia irônica ao compositor serialista americano Milton Babbitt, ao comparar os compositores conservadores, como ela, à arquitetura baiana intacta, ao passo que os "modernistas" são igualados à uma massa de concreto colocada em frente ao farol da Barra, que segundo suas palavras "esconde o céu e o mar da cidade de Salvador".

O quinto texto apresentado, Riquezas da tradição, também já havia sido publicado no Suplemento Literário de Hoje (São Paulo, 1959), sob o título "Branca Bilhar, professora de piano". Integrava uma série maior de artigos, intitulada "Riquezas da tradição”. Nele, Eunice Katunda discorre sobre o período em que teve aulas de piano com 
Branca Bilhar em um pensionato para jovens estudantes de música, na casa de Don'Anna, tia da própria Branca, no Rio de Janeiro. Dentre os relatos, destaca-se o trecho em que Eunice afirma que aprendeu a amar e apreciar certos aspectos da música brasileira por conta da influência de sua professora Branca. Ressalta o episódio em que Sátiro Bilhar, tio de Branca, tocou violão e cantou para ela e outras estudantes na casa de Don'Anna, assim como evidencia as composições de Branca e seu conteúdo nacional, que em suas palavras era "uma música de improviso, que brotava inteira de seu espírito de brasileira, vibrante e apaixonada”.

O último texto do capítulo não possui título e nem data de redação. No entanto, Kater o nomeia como Auto-retrato, assim como atribui a ele uma datação do início da década de 80. Este pequeno texto, de uma página e meia, se refere à uma reflexão de Eunice acerca de sua personalidade e de sua vida. Em certos trechos, ela aponta a amargura que sente quando percebe que não conseguiu objetivar, em realização, nem metade do que poderia ter feito; destaca também a relação com a sua mãe Grauben, assim como a admiração e lição que teria aprendido após sua morte.

O livro também traz, de forma inédita, um Catálogo de obras da compositora. O Catálogo, apresentado por ordem cronológica de composição, compreende obras compostas por Eunice, assim como peças de outros autores, que foram arranjadas, adaptadas e/ou orquestradas por ela. Como exemplo, é possível citar dentre estas obras orquestradas, os Choros n. 5, de Villa-Lobos, e Peixes de prata, de Gilberto Mendes.

Os verbetes do Catálogo apresentam informações do local (cidade) e data de composição de cada obra, número de páginas da partitura, duração média da peça, formação instrumental, dados de estreia, entre outras observações. Por fim, o Catálogo também conta com um índice remissivo, realizado a partir do meio expressivo das peças (instrumentos) e também por ordem alfabética.

Uma lista de Correspondências destinadas a Eunice Katunda, contendo nomes dos(das) signatários(as), locais e datas das cartas e o número de páginas de cada uma delas, é disponibilizada após o índice remissivo. É importante destacar que a lista traz apenas a classificação das correspondências, das quais algumas são disponibilizadas na parte de Anexos do livro.

Entre os anexos estão, por exemplo, cartas e cartões postais de Arnaldo Estrela, H. Scherchen, Koellreutter e Ricardo Malipiero, além da carta de apresentação de Eunice Katunda como pianista escrita por Guiomar Novaes para sua viagem aos EUA. Complementam esta seção as páginas iniciais das peças para piano Variações sobre um tema popular e Três momentos em New York da compositora, além de um trecho do 
manuscrito de planejamento da referente à sua $8^{\mathrm{a}}$ aula ministrada no Departamento de Música da Universidade de Brasília em 1973.

As páginas finais trazem o manuscrito completo da obra Negrinho do pastoreio (1946), uma cantata para vozes femininas a capela ou com acompanhamentos ocasionais de violão, flauta e percussão (timpani, reco-reco, matraca e triângulo), sobre o texto de Zora Seljan. É importante frisar que a partitura disponibilizada no livro consiste na cópia definitiva da obra, realizada em 1979.

Como consideração final, esta resenha aponta a relevância da publicação do livro Eunice Katunda: musicista brasileira, que ao divulgar a vida, obra e as diferentes atividades desenvolvidas por Eunice Katunda ao longo do século XX, abriu portas para muitas outras pesquisas acadêmicas acerca de sua produção composicional. A título de exemplo é possível citar a tese de doutorado Eunice Katunda (1915-199o) e Esther Scliar (1926-1978): trajetórias individuais e análise de 'Sonata de Louvação' (1960) e 'Sonata para piano' (1961) (2006), de Joana Cunha de Holanda; a dissertação de mestrado $A$ obra para canto e piano de Eunice Katunda: três momentos (2009), de Melina de Lima; e a tese de doutorado Louvação a Eunice: um estudo de análise da obra para piano de Eunice Katunda (2009), de Iracele Aparecida Vera Lívero de Souza. Destacam-se também as pesquisas de mestrado (2015), doutorado (2014) e pós-doutorado (2018) das pesquisadoras Marisa Milan Candido e Eliana M. A. Monteiro da Silva, na qual se encontram análises de peças para piano compostas por Eunice Katunda, assim como o pós doutorado de Michelle Agnes Magalhães (2014) a respeito da correspondência entre Katunda e Luigi Nono denominado A correspondência Katunda-Nono (1949-1953): o papel de Eunice Katunda na formação de Luigi Nono.

O livro aqui apresentado encontra-se esgotado nas livrarias brasileiras. De acordo com informações do próprio Kater, em breve uma nova edição será lançada em forma de e-book. 


\section{Referências}

CANDIDO, Marisa Milan. Estéticas cruzadas: rupturas e deslocamentos em Cláudio Santoro, César Guerra-Peixe e Eunice Katunda a partir de obras para piano compostas entre 1948 e 1952. Dissertação de mestrado. Universidade de Campinas, SP, 2017.

HOLANDA, Joana Cunha de. Eunice Katunda (1915-199o) e Esther Scliar (1926-1978): trajetórias individuais e análise de "Sonata de Louvação" (1960) e "Sonata para Piano" (1961). Tese (Doutorado em Música) - Universidade Federal do Rio Grande do Sul, Porto Alegre, 2005.

KATER, Carlos. Catálogo de obras H. J. Koellreutter. Belo Horizonte: Fundação de educação artística/FAPEMIG, 1997.

São Paulo: Musa, 2001.

. Música Viva e H.- J. Koellreutter: movimentos em direção à modernidade.

MARIZ, Vasco. História da música no Brasil. 5. ed. revisada e ampliada. Rio de Janeiro: Nova Fronteira, 2000.

MONTEIRO DA SILVA, Eliana Maria de Almeida. Beatriz Balzi e o piano da América Latina: a música erudita deste continente analisada a partir das gravações da pianista na série de CDs Compositores Latino-Americanos. Tese (Doutorado em Música) Universidade de São Paulo, São Paulo, 2014.

Compositoras latino-americanas: vida, obra, análise de peças para piano. 2018. Pós-Doutorado - Universidade de São Paulo, 2018.

NEVES, José Maria. Música Contemporânea Brasileira. São Paulo: Ricordi Brasileira, 1981 ( $1^{\mathrm{a}}$ edição); $2^{\mathrm{a}}$ edição revista e ampliada por Salomea Gandelman. Rio de Janeiro: Contra Capa, 2008.

PEIXOTO, Melina de Lima. A obra para canto e piano de Eunice Katunda: três momentos. Dissertação (Mestrado) - Programa de Pós-Graduação da Escola de Música da Universidade Federal de Minas Gerais, Belo Horizonte, 2009.

SOUZA, Iracele Vera Lívero. Louvação a Eunice: um estudo de análise de obras para piano de Eunice Katunda. Tese (Doutorado) - Instituto de Artes, Universidade Estadual de Campinas, Campinas, 2009. 